\title{
Associations between Pathological Internet Use and Depression, Anxiety, and Suicidality among College Students
}

\author{
Ahyoung Yoon, BSc ${ }^{1}$, Young-Eun Jung, MD, $\mathrm{PhD}^{2}$, Moon-Doo Kim, MD, PhD² \\ ${ }^{1}$ Jeju National University School of Medicine, ${ }^{2}$ Department of Psychiatry, Jeju National University School of Medicine, Jeju, Korea
}

\begin{abstract}
Background: The Internet has become an important global tool used by diverse age groups, especially adolescents and young adults. However, in South Korea, studies on the prevalence of pathological Internet use (PIU) among college students are limited to being compared with those involving adolescents. Therefore, in this report, we assessed the pervasiveness of PIU and its related factors among college students.

Methods: Data were collected from 1,390 college students. PIU was screened using the Self-Report Scale for Measuring Behavior Symptoms of Adults' PIU. We analyzed the associations between PIU and depression, anxiety, and suicidality. We also used the self-report questionnaire to assess sociodemographic and other clinical factors.

Results: Of the total number of participants, $16.8 \%(n=234)$ were identified as problematic Internet users. Univariate analysis revealed significant associations between depression, anxiety, suicidal behavior, and PIU. Multivariate analysis further showed a significant relation between unsatisfactory school life (odds ratio [OR], 2.56; 95\% confidence interval $[\mathrm{Cl}], 1.06-6.15 ; \mathrm{p}=0.036)$, depression $(\mathrm{OR}, 1.67 ; 95 \% \mathrm{Cl}, 1.03-2.71 ; \mathrm{p}=0.036)$, and anxiety $(\mathrm{OR}, 3.36 ; 95 \%$ $\mathrm{Cl}, 1.91-5.93 ; p<0.001$ ) with PIU.

Conclusion: Depression, anxiety, and suicidality are common in individuals engaged in PIU, with a complex interrelation. Further studies are required to clarify the mechanisms of PIU and develop preventive and treatment strategies.
\end{abstract}

Keywords Pathological Internet use; Depression; Anxiety; Suicidality; College students

\section{INTRODUCTION}

In recent years, Internet has been used worldwide and has become an essential tool, especially for younger age groups. It is important to explore Internet-use habits and any influence they can have on users. Although a term accurately describing the clinical features of Internetrelated behavioral problems is not yet available, it can be generally defined as: "Use of Internet that cannot be controlled and that produces psychological, social, academic, and/or work problems", and it has been described by various terms such as Internet addiction, compulsive Internet use, problematic Internet use, and pathological
Internet use (PIU) [1,2]. Despite the inconsistent use of the term in the literature, the fact that PIU produces negative consequences on users is well-documented.

PIU is most relevant to adolescents and young adults. According to 2014 statistics on Internet addiction in South Korea, the highest risk group were adolescents (12.5\%), while adults were second (5.8\%) [3]. Park et al. [4] reported that adolescents in South Korea who met the criteria for PIU were at significantly increased risk for depression and suicidal ideation. For adults, PIU can result in worse consequences than in adolescents. Recent studies in the United States and Hong Kong have explored the relationships between PIU and family

Received June 22, 2020, Revised July 4, 2020, Accepted July 5, 2020

Correspondence: Moon-Doo Kim, MD, PhD

Department of Psychiatry, Jeju National University School of Medicine, 102 Jejudaehak-ro, Jeju 63243, Korea

TEL +82-64-717-1234 FAX +82-64-717-1849 E-mail mdkim66@jejunu.ac.kr ORCID https://orcid.org/0000-0002-6441-630X

Copyright $\odot$ by Korean Society for Affective Disorders. All Rights reserved.

This is an Open Access article distributed under the terms of the Creative Commons Attribution Non-Commercial License (http://creativecommons.org/licenses/ by-nc/4.0/) which permits unrestricted non-commercial use, distribution, and reproduction in any medium, provided the original work is properly cited. 
relationships and sleep problems among college students [5,6]. In South Korea, Kim et al. [7] reported an increased risk of depression and anxiety in the Internet addiction group aged 19 to 39 years. Since college students are especially vulnerable to developing PIU, we evaluated the prevalence of PIU in college students in the Jeju area, and its relationship to psychiatric symptoms including depression, anxiety, and suicidality.

\section{MATERIALS AND METHODS}

\section{Participants}

In this study, the researchers sent letters, including a statement explaining the purpose of the study, to colleges located in the Jeju Special Self-Governing Province, South Korea. Four colleges agreed with the purpose of the study, and the researchers received written informed consent from a total of 1,416 college students aged 18 years or older, who completed a self-administered questionnaire. The study was performed with the assistance of 8 research assistants, including social workers and psychiatric nurses. They explained to the participants the purpose of the survey and provided directions for participants to answer the survey questionnaires, which included several self-report screening instruments. This study was approved by the Institutional Review Board of Jeju National University Hospital (IRB No. JEJUNUH 2018-10-009-001). A total of 26 subjects were excluded because their responses were incomplete, thus leaving a total of 1,390 subjects for the final analysis.

\section{Assessment}

A self-report questionnaire was used to obtain information regarding various sociodemographic, traumarelated, and clinical symptom-related variables. The variables include age, sex, parental marital status, selfreported socioeconomic status (SES), school records, satisfaction with school life and familial relationships, a history of childhood adversity (including physical or sexual abuse by other people, and school bullying), and previous history of psychiatric disorders. Body mass index $\left(\mathrm{BMI}=\right.$ weight $[\mathrm{kg}] /$ square of height $\left.\left[\mathrm{m}^{2}\right]\right)$ was calculated based on self-reported weight and height, and subjects with $\mathrm{BMI} \geq 25$ were classified as overweight or obese [8]. We administered the Alcohol Use Disorder
Identification Test-Alcohol Consumption instrument to assess the severity of alcohol use problems. A cutoff score of 8 was used in this study to represent significant alcohol use problems [9].

To screen for PIU, we used the Self-Report Scale for Measuring Behavioral Symptoms of Adults' PIU. This scale is a screening tool for Internet addiction among adults composed of 20 items. It has high internal consistency (Cronbach's $\alpha=0.87$ ) and consists of four factors including virtual reality, distraction and mood alteration, tolerance and preoccupation, and feeling guilty for Internet use. A cutoff score of 43 was adopted to detect PIU in this study [10].

To obtain information regarding depression, anxiety, and suicidality, we administered the Patient Health Questionnaire-9 (PHQ-9), the Generalized Anxiety Disorder Screener (GAD-7), and the Suicide module of the Mini International Neuropsychiatric Interview (M.I.N.I.). Depression was identified using the PHQ-9, which is a reliable screening tool for measuring depressive symptoms and severity over the past 2 weeks. The PHQ-9 is composed of nine items rated from 0 (not at all) to 3 (having the symptoms nearly every day), and the scores for each item are summed to produce a total depression severity score (range: 0-27) [11]. The Korean version of the PHQ-9 has high internal consistency (Cronbach's $\alpha=0.831$ ) [12], and participants in this study were identified as having depression if their total score of the PHQ-9 score was $\geq 10[11,12]$. The GAD-7 is a one-dimensional instrument designed to detect anxiety symptoms. The item scores ranged from 0 (not at all) to 3 (nearly every day), resulting in a sum score range from 0 to 21. A cutoff score of 10 was adopted to detect any significant anxiety symptoms in this study [13]. The Suicide module of the M.I.N.I., which was used to evaluate suicide risk, includes six questions that assess suicidal ideation within the past month ("Have you thought you would be better off dead or wished you were dead?"; "Have you wanted to harm yourself?"; and "Have you thought about suicide?), suicide plans within the past month ("Did you have a suicide plan?"), suicide attempts within the past month ("Have you attempted suicide?"), and lifetime suicide attempts ("In your lifetime, have you ever attempted suicide?"). The score for each answer was weighted according to its importance in assessing suicide risk $[14,15]$. 


\section{Statistical analysis}

The Pearson chi-square test and independent t-test were used to compare the proportions and means of the independent variables versus dependent variables. For the correlation analyses, univariate associations were investigated between independent variables and PIU. Factors potentially associated with PIU on univariate analyses were then entered simultaneously into a logistic regression model to assess independence. Odds ratios (ORs) and 95\% confidence intervals (CIs) were derived from a series of logistic regression analyses. All statistical analyses were performed using IBM SPSS Statistics for Windows, Version 25.0 (IBM Co., Armonk, NY, USA), and statistical significance was determined using an alpha level of 0.05 (two-tailed tests).

Table 1. Comparisons of characteristics among subjects with and without PIU among college students

\begin{tabular}{|c|c|c|c|}
\hline Variable & Normal users $(n=1,156)$ & PIUs ( $n=234)$ & $p$-value \\
\hline Age $(y)$ & & & 0.417 \\
\hline$\leq 20$ & $591(51.1)$ & $130(55.6)$ & \\
\hline $21-24$ & $490(42.4)$ & $92(39.3)$ & \\
\hline$\geq 25$ & $75(6.5)$ & $12(5.1)$ & \\
\hline Sex & & & 0.069 \\
\hline Male & $484(41.9)$ & $83(35.5)$ & \\
\hline Female & $672(58.1)$ & $151(64.5)$ & \\
\hline Parental marital status & & & 0.365 \\
\hline Married & $894(77.5)$ & $190(81.2)$ & \\
\hline Divorced/separated & $194(16.8)$ & $35(15.0)$ & \\
\hline Widowed & $66(5.7)$ & $9(3.8)$ & \\
\hline Self-reported SES & & & 0.620 \\
\hline High & $229(19.8)$ & $40(17.1)$ & \\
\hline Middle & $794(68.7)$ & $164(70.1)$ & \\
\hline Low & $132(11.4)$ & $29(12.4)$ & \\
\hline School records & & & 0.054 \\
\hline Above average & $337(29.2)$ & $72(30.8)$ & \\
\hline Average & $633(54.8)$ & $111(47.4)$ & \\
\hline Below average & $186(16.1)$ & $51(21.8)$ & \\
\hline Satisfaction with school life & & & $<0.001 x$ \\
\hline Very unsatisfied & $21(1.8)$ & $6(2.6)$ & \\
\hline Unsatisfied & $87(7.5)$ & $39(16.7)$ & \\
\hline Average & $512(44.3)$ & $107(45.7)$ & \\
\hline Satisfied & $452(39.1)$ & 76 (32.5) & \\
\hline Very satisfied & $84(7.3)$ & $6(2.6)$ & \\
\hline Family emotional support & & & $0.001 x$ \\
\hline No support & $21(1.8)$ & $8(3.4)$ & \\
\hline Frequent support & $298(25.9)$ & $86(36.8)$ & \\
\hline Sufficient support & $832(72.3)$ & $140(59.8)$ & \\
\hline History of physical abuse & $120(10.4)$ & $44(18.8)$ & $<0.001 x$ \\
\hline History of sexual abuse & $17(1.5)$ & $7(3.0)$ & 0.162 \\
\hline History of school bullying & $145(12.6)$ & $48(20.6)$ & $0.001 x$ \\
\hline Previous psychiatric history & $50(4.3)$ & $17(7.4)$ & 0.052 \\
\hline Overweight or obesity & $208(21.1)$ & $43(20.5)$ & 0.831 \\
\hline Problematic alcohol use & $352(30.5)$ & $78(33.6)$ & 0.353 \\
\hline
\end{tabular}

Values are presented as number (\%) and different subtotal because of missing.

PIU, pathological Internet use; SES, socioeconomic status.

*Statistically significant difference. 


\section{RESULTS}

Of the 1,390 participants, 567 males (40.8\%) and 823 females $(59.2 \%)$ were included; $51.9 \%$ were under the age of $20,41.9 \%$ were between the ages of 21 and 24 years, and the remaining (6.2\%) were aged 25 years or older. A total of 164 participants (11.8\%) had histories of physical abuse, and 193 participants (13.9\%) had histories of school bullying. Previous psychiatric histories were reported by a total of 67 participants (4.8\%).

We found that $16.8 \%$ of all participants were PIUs, and histories of childhood adversity were significantly related to PIU; the p-value for a history of physical abuse was $<0.001$, and that of a history of school bullying was 0.001 . Moreover, it is important to note that there were significant differences between normal users and PIUs in terms of satisfaction with school life $(p<0.001)$ and family emotional support $(\mathrm{p}=0.001)$; PIUs reported having a more unsatisfactory school life (very unsatisfied $=2.6 \%$ ) and less family emotional support (no support $=3.4 \%$ ) than normal users (very unsatisfied $=1.8 \%$, no support $=1.8 \%$ ). Age, sex, parental marital status, selfreported SES, overweight or obesity, and problematic alcohol use were not related to PIU (Table 1).

The PHQ-9, the GAD-7, and the M.I.N.I. suicidal risk scores were significantly higher in PIUs than normal users. A total of 153 college students (11.0\%) had positive PHQ-9 scores, suggestive of depression. Likewise, GAD-7 scores suggesting anxiety symptoms were positive in a total of 82 college students $(5.9 \%)$. Univariate analysis revealed significant associations between depression and PIU $(p<0.001)$, and anxiety and PIU $(\mathrm{p}<0.001)$. Moreover, the prevalence of lifetime suicidal behaviors (suicidal ideation, plan, and attempt) was also significantly associated with PIU ( $<<0.001$; Table 2 ).

Table 3 shows multivariate associations between the independent variables and PIU. After adjusting for age, sex, and previous psychiatric history, the results showed that unsatisfactory school life (OR, 2.56; 95\% CI, 1.06$6.15 ; \mathrm{p}=0.036)$, presence of depression (OR, 1.67; 95\% CI, 1.03-2.71; $\mathrm{p}=0.036$ ), and presence of anxiety symptoms (OR, 3.36; 95\% CI, 1.91-5.93; $\mathrm{p}<0.001)$ were significantly related to PIU.

\section{DISCUSSION}

The results of this study enhance our understanding of the relationship between PIU and psychological symptoms in college students. Our results showed that among college students in the Jeju area, $16.8 \%$ were engaged in PIU and it was significantly associated with various factors including family environment and psychological states. We found that this prevalence is higher than that of previous studies performed with young adults. Among Korean adults aged 18 to 64 years, the prevalence of PIU was 9.3\% [16], and in a Spanish study $6.4 \%$ of college students engaged in PIU [17]. Similarly, the prevalence of PIU among Chinese college students was $10.2 \%$ [18], and among the $3.1 \%$ of Slovenian adult Internet users who are at risk of becoming problematic Internet users, $11 \%$ of them belonged to the age group

Table 2. Comparisons of depression, anxiety, and suicidality among subjects with and without PIU among college students

\begin{tabular}{lccc}
\hline \multicolumn{1}{c}{ Variable } & Normal users $(n=1,156)$ & PIUs $(n=234)$ & $p$-value \\
\hline Depression & & & \\
PHQ-9 positive & $95(8.2)$ & $68(24.8)$ & $<.94 \pm 5.34$ \\
PHQ-9 total score & $3.51 \pm 3.94$ & & $<0.001 *$ \\
Anxiety & & $41(17.5)$ & $<0.001 *$ \\
GAD-7 positive & $41(3.6)$ & $5.12 \pm 4.66$ & $<0.001 *$ \\
GAD-7 total score & $2.42 \pm 3.21$ & & $<0.001 *$ \\
Suicidality & & $92(39.3)$ & $<0.001 *$ \\
Lifetime suicidal behaviors, yes & $210(18.2)$ & $3.00 \pm 4.84$ & $1.27 \pm 3.71$ \\
M.I.N.I. suicidal risk score &
\end{tabular}

Value are presented as number (\%) or mean \pm standard deviation.

PIU, pathological Internet use; PHQ-9, the Patient Health Questionnaire-9; GAD-7, the Generalized Anxiety Disorder Screener; M.I.N.I., the Suicide module of the Mini International Neuropsychiatric Interview.

*Statistically significant difference. 
Table 3. Factors associated PIU among college students

\begin{tabular}{|c|c|c|}
\hline \multirow{2}{*}{ Variable } & \multicolumn{2}{|c|}{ Normal versus PIUs } \\
\hline & OR $(95 \% \mathrm{Cl})$ & $\mathrm{p}$-value \\
\hline \multicolumn{3}{|l|}{ Sex (reference: male) } \\
\hline Female & $1.12(0.84-1.57)$ & 0.387 \\
\hline \multicolumn{3}{|c|}{ Satisfaction with school life (reference: very satisfied) } \\
\hline Very unsatisfied & $2.19(0.91-5.28)$ & 0.082 \\
\hline Unsatisfied & $2.56(1.06-6.15)$ & $0.036 *$ \\
\hline Average & $4.34(1.68-11.21)$ & $0.002 \star$ \\
\hline Satisfied & $2.18(0.59-8.03)$ & 0.240 \\
\hline \multicolumn{3}{|c|}{ Family emotional support (reference: sufficient support) } \\
\hline No support & $1.33(0.53-3.33)$ & 0.547 \\
\hline Frequent support & $1.20(0.86-1.67)$ & 0.283 \\
\hline History of physical abuse & $1.39(0.90-2.15)$ & 0.139 \\
\hline History of school bullying & $1.29(0.85-1.95)$ & 0.230 \\
\hline Previous psychiatric history & $1.26(0.64-2.49)$ & 0.498 \\
\hline PHQ-9 positive & $1.67(1.03-2.71)$ & $0.036 *$ \\
\hline GAD-7 positive & $3.36(1.91-5.93)$ & $<0.001 *$ \\
\hline
\end{tabular}

PIU, pathological Internet use; OR, odds ratio; Cl, confidence interval; PHQ-9, Patient Health Questionnaire-9; GAD-7, Generalized Anxiety Disorder Screener.

*Statistically significant difference.

from 20 to 24 years [19]. However, it is difficult to compare our results with those of other prevalence studies because of the application of different measuring tools, regional characteristics, and cultural differences.

Similar to other studies, we found that college students engaged in PIU showed significant associations with childhood adversity and a lack of family emotional support. According to previous studies with adolescents, victims of bullying including cyber-bullying were more likely to develop PIU than peers who were not involved in bullying, and adolescents having poor communication with their parents were prone to PIU [20-22]. A history of sexual abuse also predicted PIU in adolescents [23]. In the case of college students, there are some reports that less-caring parents or conflicts with parents are related to PIU, and suggest that individuals who engaged in PIU may seek social support through the Internet by making online relationships [5,19]. Given that the target population of numerous existing studies on PIU and its risk factors are adolescents, our findings warrant further investigations to young adults who engage in PIU and possible temporal relationships of associated factors and PIU.

The present study showed that college students who engaged in PIU also manifested a significant risk of psychiatric symptoms such as depression and anxi- ety. This result is consistent with previous findings $[1,4,6,7,17,19,23,24]$. Kim et al. [7] showed an increased risk of depression and anxiety in Korean adults aged 19 to 49 years who are addicted to the Internet. Yang et al. [19] suggested that individuals engaged in PIU may use the Internet to escape from stressful events and to cope with real-life difficulties. They might seek online relationships to relieve or hide their negative feelings and anxiety originating from their inadequate relationships in reality [1]. Many studies have also stated that PIU increases the risk of psychiatric disorders; more severe PIU, results in worse psychiatric symptoms $[4,6,19]$. Kim et al. [7] explained the role of internet addiction in developing depression and anxiety. First, Internet addiction and PIU can cause complications with family and friends, since most of their time is devoted to cyberspace. Second, the withdrawal symptoms of Internet addiction is comparable to substance-use disorders and lastly, addicts may not be aware of their excessive use because their access to devices are relatively free and flexible [7]. Individuals engaged in PIU also tend to have a history of psychiatric disorders, such as depression, anxiety, bipolar disorder, and impulse control disorder, and these disorders could predict PIU [23-25]. Psychiatric symptoms are not only affected by PIU but can also result in development of PIU. Thus, it is impor- 
tant to observe interactive relationships between psychiatric disorders and PIU.

Consistent with previous studies $[4,17,26]$, our finding also showed that college students engaged in PIU had higher suicidality than normal Internet users. Regarding depression and anxiety, one study with Korean adolescents showed that PIU could predict suicidal ideation, and suicidal ideation could also predict PIU [4]. In addition, in individuals engaged in PIU, suicidal behaviors such as suicidal ideation, plans, and attempts were higher than in normal users [17,26]. Many studies showed that suicidality often occurs along with other psychiatric disorders in individuals engaged in PIU; these findings suggest that these factors are all interconnected and could possibly have reinforcing interactions.

This study has the following limitations. First, it is difficult to explore the causal relationship between PIU and related factors, since this is a cross-sectional study. A prospective study is required to classify PIU as a predictive factor for depression, anxiety, and suicidality. Second, measures of PIU and psychiatric symptoms were based on self-report rather than clinical evaluation. Lastly, this study was conducted in college students in a specific area, so it is difficult to generalize the research results.

\section{CONCLUSIONS}

The present study observed factors associated with college students who engage in PIU. Most importantly, individuals engaged in PIU had significant risks for depression, anxiety, and suicidality, and these psychiatric problems and PIU seemed to have an effect in both directions. Because the comorbidity rate is high between PIU and many psychiatric symptoms, prospective studies based on different sampling groups will enhance our understanding of the mechanisms that influence PIU and allow us to investigate preventive intervention strategies.

\section{CONFLICTS OF INTEREST}

The authors have nothing to disclose.

\section{ORCID}

\author{
Ahyoung Yoon \\ https://orcid.org/0000-0002-6498-4462 \\ Young-Eun Jung \\ https://orcid.org/0000-0001-7608-0009 \\ Moon-Doo Kim \\ https://orcid.org/0000-0002-6441-630X
}

\section{ACKNOWLEDGEMENTS}

This work was supported by the 2020 education, research and student guidance grant funded by Jeju National University.

\section{REFERENCES}

1. Anderson EL, Steen E, Stavropoulos V. Internet use and problematic internet use: a systematic review of longitudinal research trends in adolescence and emergent adulthood. Int J Adolesc Youth 2017;22:430-54.

2. Poli R. Internet addiction update: diagnostic criteria, assessment and prevalence. Neuropsychiatry 2017;7:4-8.

3. National Information Society Agency. 2014 A survey on internet addiction. Seoul: National Information Society Agency; 2015.

4. Park S, Hong KE, Park EJ, Ha KS, Yoo HJ. The association between problematic internet use and depression, suicidal ideation and bipolar disorder symptoms in Korean adolescents. Aust N Z J Psychiatry 2013;47:153-9.

5. Snyder SM, Li W, O'Brien JE, Howard MO. The effect of U.S. university students' problematic internet use on family relationships: a mixed-methods investigation. PLoS One 2015;10:e144005.

6. Wong HY, Mo HY, Potenza MN, Chan MNM, Lau WM, Chui TK, et al. Relationships between severity of internet gaming disorder, severity of problematic social media use, sleep quality and psychological distress. Int J Environ Res Public Health 2020;17:1879.

7. Kim YJ, Jang HM, Lee Y, Lee D, Kim DJ. Effects of internet and smartphone addictions on depression and anxiety based on propensity score matching analysis. Int $\mathrm{J}$ Environ Res Public Health 2018;15:859.

8. Kanazawa M, Yoshiike N, Osaka T, Numba Y, Zimmet P, Inoue S. Criteria and classification of obesity in Japan and Asia-Oceania. World Rev Nutr Diet 2005;94:1-12.

9. Gordon AJ, Maisto SA, McNeil M, Kraemer KL, Conigliaro RL, Kelley ME, et al. Three questions can detect hazardous drinkers. J Fam Pract 2001;50:313-20.

10. Lee HC, Choi YK, Lee SM, Ban JC, Lee SY. Development 
of a self-report scale for measuring behavioral symptoms of adults` pathological internet use. Korean J Clin Psychol 2007;26:765-91.

11. Kroenke K, Spitzer RL, Williams JB. The PHQ-9: validity of a brief depression severity measure. J Gen Intern Med 2001;16:606-13.

12. Yoon S, Lee Y, Han C, Pae CU, Yoon HK, Patkar AA, et al. Usefulness of the patient health questionnaire-9 for Korean medical students. Acad Psychiatry 2014;38:661-7.

13. Spitzer RL, Kroenke K, Williams JB, Löwe B. A brief measure for assessing generalized anxiety disorder: the GAD-7. Arch Intern Med 2006;166:1092-7.

14. Sheehan DV, Lecrubier Y, Sheehan KH, Amorim P, Janavs J, Weiller E, et al. The Mini-International Neuropsychiatric Interview (M.I.N.I.): the development and validation of a structured diagnostic psychiatric interview for DSM-IV and ICD-10. J Clin Psychiatry 1998;59 Suppl 20:22-33; quiz 34-57.

15. Yoo SW, Kim YS, Noh JS, Oh KS, Kim CH, Namkoong K, et al. Validity of Korean version of the mini-international neuropsychiatric interview. Anxiety Mood 2006;2:50-5.

16. Carbonell X, Chamarro A, Oberst U, Rodrigo B, Prades M. Problematic use of the internet and smartphones in university students: 2006-2017. Int J Environ Res Public Health 2018;15:475.

17. Kim BS, Chang SM, Park JE, Seong SJ, Won SH, Cho MJ. Prevalence, correlates, psychiatric comorbidities, and suicidality in a community population with problematic internet use. Psychiatry Res 2016;244:249-56.

18. Macur M, Király O, Maraz A, Nagygyörgy K, Demetrovics Z. Prevalence of problematic internet use in Slovenia. Zdr
Varst 2016;55:202-11.

19. Yang CY, Sato T, Yamawaki N, Miyata M. Prevalence and risk factors of problematic internet use: a cross-national comparison of Japanese and Chinese university students. Transcult Psychiatry 2013;50:263-79.

20. Boniel-Nissim M, Sasson H. Bullying victimization and poor relationships with parents as risk factors of problematic internet use in adolescence. Comput Human Behav 2018; 88:176-83.

21. Gámez-Guadix M, Orue I, Smith PK, Calvete E. Longitudinal and reciprocal relations of cyberbullying with depression, substance use, and problematic internet use among adolescents. J Adolesc Health 2013;53:446-52.

22. Jung YE, Leventhal B, Kim YS, Park TW, Lee SH, Lee M, et al. Cyberbullying, problematic internet use, and psychopathologic symptoms among Korean youth. Yonsei Med J 2014;55:826-30.

23. Kim BN, Park S, Park MH. The relationship of sexual abuse with self-esteem, depression, and problematic internet use in Korean adolescents. Psychiatry Investig 2017;14: 372-5.

24. Shapira NA, Goldsmith TD, Keck PE Jr, Khosla UM, McElroy SL. Psychiatric features of individuals with problematic internet use. J Affect Disord 2000;57:267-72.

25. Mazhari S. The prevalence of problematic internet use and the related factors in medical students, Kerman, Iran. Addict Health 2012;4:87-94.

26. Alpaslan AH, Avci K, Soylu N, Guzel HI. The association between problematic internet use, suicide probability, alexithymia and loneliness among Turkish medical students. J Psychiatry 2015;18:1. 